\title{
Russell's Method of Analysis and the Axioms of Mathematics
}

\author{
Lydia Patton
}

The mathematician is only strong and true as long as he is logical, and if number rules the world, it is logic which rules number.

-William Stanley Jevons, Principles of Science (1874).

\section{Mathematical Axioms and the Logocentric Predicament}

Bertrand Russell's approach in Principia Mathematica and elsewhere often is taken as definitive of logicism, or even of "Frege-Russell logicism." According to the logicist approach, mathematics can be (and ought to be) derived from logic, using inferences governed by logical laws. With Frege, Russell distinguished logical laws from the laws of thought and from psychology generally, which distinguishes logicism

\section{Patton $(\bowtie)$}

Virginia Tech, 231 Major Williams Hall, Blacksburg, VA 24061, USA e-mail: critique@vt.edu

S. Lapointe and C. Pincock (eds.), Innovations in the History of Analytical Philosophy,

Palgrave Innovations in Philosophy, DOI 10.1057/978-1-137-40808-2_4 
from an earlier tradition found in Boole's The Laws of Thought, and in the Kantian logicians Erdmann and Sigwart.

On a well-known reading, Russell interprets the laws of logic as universal, true, a priori conditions for the derivation of the results of logic and of mathematics. On this reading, Russell appeals to deduction from the laws - taken as a priori truths - as the sole ground of justification for inferences in logic and in mathematics. We might conclude that the fact that we can derive mathematical results from them deductively is a justification of the logical laws themselves. And we might transfer this axiomatic justification to the axioms of mathematics, as they are applied in that science. The axioms of mathematics would be for Russell a set of truths derived from logic, which do not stand in need of further justification.

From Sheffer and Wittgenstein onward, the objection has been made that Frege's and Russell's logicist methods do not even allow for an epistemic, scientific, or external justification for the laws of logic or, by extension, for the axioms of mathematics. Logic is seen as a "first science," as the science that founds the others. Moreover, since logic is treated as a universal language of ultimate generality, there is no perspective from outside of logic — no meta-perspective-from which to evaluate the truth or the validity of the logical laws.

Frege's and Russell's systems are meant to provide a universal language: a framework inside of which all rational discourse proceeds. Thus there can be no position outside the system from which to assess it. The laws they derive are general laws with fixed sense; questions of disinterpretation and reinterpretation cannot arise. All this distinguishes their conception of logic from that more common today, which relies on schematization and interpretation and defines logical truth by reference to schemata. [...] Frege and Russell can have no notion of "interpretation," or of "semantics." The text surrounding their formulas is at best heuristic, aimed at initiating their audience into their languages (Goldfarb 1982, 694; cited in Korhonen 2012, 599).

In a review of Principia Mathematica, Harry Sheffer objected that the logicist project involves a circle, which he dubs the "logocentric 
predicament": "In order to give an account of logic, we must presuppose and employ logic" $(1926,228)$. Proving that logical statements are true requires proving that they are truths within logic itself, within the systems constructed by Frege and Russell. But, since logic is the universal language of rational discourse, any project of justification must stop there. There is no way to re-interpret the statements of logic, no metalanguage or meta-perspective within which we consider candidate logical systems, for instance, and assess the basis for truth claims within each. An optimist might conclude that logic is its own basis, while a skeptic will conclude that the question of justification leads to a regress without resolution (see Ricketts 1985, Quine 1936/1976, Gillian Russell 2014, \$3.1.1).

For Frege, the univocity of sense and reference of his logical propositions was a virtue, and it even extended to mathematical propositions. Frege carefully distinguished the laws of logic from schematic axioms and from rules of inference. ${ }^{1}$ In particular, the laws of logic, for Frege, are univocal, uninterpretable, and universal truths. Fregean logical laws are purely general and do not apply to, nor are they derived from, any particular subject matter (Blanchette 2012, 74-75, 127-128; Frege $1884 / 1994, \$ 64)$. Moreover, in his debates with Hilbert over the foundations of geometry, Frege argued that the propositions of geometry were not susceptible to multiple interpretations and that the axioms of geometry should express univocal truths.

Russell, on the other hand, did not make Frege's distinction between laws of logic and rules of inference (Ricketts 1985, 4-7 and passim). Moreover, as Kremer (2006) and others have emphasized, Frege and Russell had distinct interpretations of analyticity and syntheticity, and of logical justification more generally. If Frege's and Russell's logicist positions and methods are not identical, then what kind of logicist is Russell?

The question is not a mere question of classification. If Russell's logicism rests on deriving results from the laws of logic, if pure mathematics rests on proving that statements about number rest on logical implication, and if the project of justifying the laws of logic leads to an irresoluble regress (the logocentric predicament), then the project stumbles. ${ }^{2}$ 
Recent scholarship has emphasized another argumentative tendency in Russell, one that departs from Frege's methods. Irvine (2009), Godwyn and Irvine (2003), Hager (2003), and Gandon (2012) have urged that historians of philosophy take into account Russell's method of analysis and his regressive method for justifying the axioms of logic.

Firstly, philosophical analysis proceeds backward from a body of knowledge to its premisses, and, secondly, it proceeds forward from the premisses to a reconstruction of the original body of knowledge (Hager 2003, 310).

Russell refers to the first, "analytic" step as "regressive."3 The second, "synthetic" step is deductive: re-deriving the original body of knowledge from the premisses arrived at through analysis. The body of "knowledge" can be a set of observations or intuitive "truths of perception," or it can be demonstrative knowledge in mathematics or empirical science. ${ }^{4}$ The aim of the method of analysis is to derive the necessary conditions for the results under investigation and then to show that the results follow from the conditions.

The essay following traces some of the historical roots of, and motivations for, Russell's method, which in turn shed light on his view about the status of mathematical axioms. In the early 1900s, Russell began to recognize that he, and many other mathematicians, had been using assertions like the Axiom of Choice implicitly, and without explicitly proving them (see Moore 2015, lv). In working with his and Whitehead's Multiplicative Axiom, often considered to be equivalent to the Axiom of Choice, Russell came to take the position that some axioms are necessary to recovering certain results of mathematics, but may not be proven to be true absolutely.

Russell came to the position that, in the case of at least some mathematical axioms, our commitment to them as axioms need not require us to believe that they are true. This may seem un-logicist: should not the axioms be derivable from logical truths? But there is another way to think of the logicist method. It is possible to be a logicist, to consider that arithmetic is derivable from the Peano axioms, and nonetheless to argue that some mathematical axioms need not be universal, univocal a priori truths, but can have a regressive justification derived from the 
method of analysis. To a Russellian logicist, the results of mathematics can constitute evidence of a deeper set of logical relationships, and the clarification of these logical relationships can extend our knowledge, in mathematics and in logic.

Irvine (1989) summarizes the usual reading of Russell, according to which he is committed to "epistemic logicism":

According to this view, since we are epistemically justified in accepting the self-evident truths of logic, the successful identification of mathematics with logic would give us the same justification for accepting the truths of mathematics (p. 307).

Irvine emphasized that Russell's 1907 talk given at Cambridge, "The Regressive Method of Discovering the Premises of Mathematics," as well as remarks he made earlier about the paradoxes, cuts against an epistemic logicist reading of Russell:

It was with the discovery of the contradiction [in 1901] that his selfacclaimed "intellectual honeymoon" ended.. The following comment is representative and telling: "I wrote to Frege about it [the paradox] who replied that arithmetic was tottering and that he saw that his Law V was false... For my part, I felt that the trouble lay in logic rather than in mathematics and that it was logic which would have to be reformed." In the end it would be that parts of logic were to be epistemologically justified as a result of their mathematical consequences... a distinction between logical and epistemological order within mathematics would emphasize, not only the role of the regressive method, but also the close analogy that Russell saw between the epistemology of mathematics and that of the natural sciences. ${ }^{5}$

Irvine thus argues that Russell adopts a broader definition of epistemic justification, where logic is not the sole source of such justification. The question remains of how we are to understand Russell's method of analysis, if it is not in the service of epistemic logicism. In other words, if "parts of logic" are to be justified "as a result of their mathematical consequences," then how are we to understand the process of analysis and of justification? Beaney (2003) separates three modes of analysis in Russell (and in Frege): regressive, resolutive, and interpretive (154 and passim). Innovations in the History of Analytical Philosophy, edited by Sandra Lapointe, and Christopher Pincock, Palgrave 
We might put Irvine's and Beaney's readings in a broader context and argue that Russell was committed to something one could call immanent logicism. The logicism in immanent logicism is a commitment to the view that analysis of logical structures within mathematics can lead to an expansion of knowledge.

Section 2 cites an historical precedent for Russell's immanent logicism. The early logicist William Stanley Jevons, who was cited by Frege and known by Russell, took a similar view of logic and method, and of the status of the axioms of science.

Section 3 extends this precedent into the logicism of Russell and even of Frege, and shows that this broader, immanent version of logicism was a position available to, and considered by, both. Here I offer a reading of Russell's 1907 talk in Cambridge on the regressive method, and investigate how immanent logicism and the regressive method were valuable to Russell when he was evaluating the role and use of mathematical axioms (the Axiom of Choice, the Multiplicative Axiom, the Axiom of Reducibility, and others) — in the early 1900s, on the road to Principia.

\section{Early Logicism and the Methods of Science: Jevons and Venn}

William Stanley Jevons's (1874) The Principles of Science and John Venn's (1866) The Logic of Chance and (1889) The Principles of Empirical or Inductive Logic had an impact on philosophy and on science still to be measured. Margaret Schabas $(1984,1990)$ has done significant work on Jevons's place in the history of economics and of Victorian science. Laudan (1968) notes Jevons's and Venn's significance:

Jevons in particular seems to have effected a significant change in the conception of many of the problems of the philosophy of science...it would probably be true to say that modern research into confirmation theory owes its greatest debt to Jevons, who argued that the essence of inductive inference consists in the inverse application of the classical theory of probability (35). 
What Jevons refers to as "inductive inference" is directly analogous to the first step of Russell's "method of analysis," according to which,

Firstly, philosophical analysis proceeds backwards from a body of knowledge to its premisses, and, secondly, it proceeds forwards from the premisses to a reconstruction of the original body of knowledge (Hager 2003, 310).

Jevons deals with both processes in Principles of Science:

In deduction we are engaged in developing the consequences of a law. We learn the meaning, contents, results or inferences, which attach to any given proposition. Induction is the exactly inverse process. Given certain results or consequences, we are required to discover the general law from which they flow [.... all reasoning is founded on the principles of deduction [...] I shall endeavour to show that induction is really the reverse process of deduction. There is no mode of ascertaining the laws which are obeyed in certain phenomena, unless we have the power of determining what results would follow from a given law (Jevons 1874, 11-12).

In Book 2, Chapter 11, "The Philosophy of Inductive Inference," Jevons explains what he means by induction as the "inversion of deduction." Jevons proposes a method of inference that is an interesting hybrid of Herschel and Whewell:

I hold that in all cases of inductive inference we must invent hypotheses, until we fall upon some hypothesis which yields deductive results in accordance with experience. Such accordance renders the chosen hypothesis more or less probable, and we may then deduce, with some degree of likelihood, the nature of our future experience, on the assumption that no arbitrary change takes place in the conditions of nature (Jevons 1874, 228).

Calling the invention of hypotheses "induction" is owed to Whewell, the hypothesis "which yields deductive results in accordance with experience" to Herschel. ${ }^{6}$ But the following account that the result is to deduce "our future experience" "with some degree of likelihood" is Jevons's. 
In all cases, Jevons argues that the process is the same:

Being in possession of certain particular facts or events expressed in propositions, we imagine some more general proposition expressing the existence of a law or cause; and, deducing the particular results of that supposed general proposition, we observe whether they agree with the facts in question. Hypothesis is thus always employed, consciously or unconsciously. The sole conditions to which we need conform in framing any hypothesis is, that we both have and exercise the power of inferring deductively from the hypothesis to the particular results, which are to be compared with the known facts. Thus there are but three steps in the process of induction:

(1) Framing some hypothesis as to the character of the general law.

(2) Deducing consequences from that law.

(3) Observing whether the consequences agree with the particular facts under observation (Jevons 1874, 265-266).

The following features of Jevons's account should be borne in mind:

J1. The account of approximation, with particular reference to Boyle's law and the law of gravitation, and the argument that a proof or demonstration of an approximate law must prove it approximately, not exactly true-that "perfect correspondence ... should give rise to suspicion" $(1874,457)$.

J2. The account of inverse induction, as inferring laws from observed facts, including mathematical facts, and then testing the consequences of those laws against the facts.

J3. The law of gravitation as having more consequences than the phenomena of gravitation (laws as sources of fruitfulness); Jevons (1874), 259.

J4. The argument that the axioms of logic and mathematics, like the laws of physical sciences, are only probably true, but that the joint probability of those axioms, given all the other observed facts that can be derived from them, approaches certainty.

As will become clear in the section following, versions of all four claims can be found in Russell's talk in Cambridge, "The Regressive Method of Discovering the Axioms of Mathematics" (1907/1973). For my purposes, it is not crucial that any of these ideas came from Jevons. The 
point is that there were precedents for Russell's method of analysis, and even for some elements of what I've called his immanent logicism. Russell could be expected to be aware of these precedents and to have taken their proponents seriously.

\section{Russell's Regressive Method and Immanent Logicism}

Jevons's and Venn's methods of induction and deduction are not new. They are very similar to the Greek methods of analysis and synthesis in geometry, discussed by Proclus in his commentary on Euclid, for instance. Nonetheless, it is of interest that there was a renewed focus on the regressive justification of mathematical axioms just before Russell began working in the early twentieth century. Russell's method of analysis, which uses regressive or abductive inference to rise from the facts or results to principles or axioms and then derives the facts or results from those principles or axioms, is in this vein. ${ }^{7}$

Russell begins his talk, "The Regressive Method of Discovering the Principles of Mathematics," read to the Cambridge Mathematical Club on March 9, 1907, with the following remark:

My object in this paper is to explain in what sense a comparatively obscure and difficult proposition may be said to be a premise for a comparatively obvious proposition, to consider how premises in this sense may be discovered, and to emphasise the close analogy between the methods of pure mathematics and the methods of the sciences of observation (Russell 1907/1973, 272).

The axioms and rules of logic, Russell points out, are more complicated than their relatively simple arithmetical consequences:

There is an apparent absurdity in proceeding, as one does in the logical theory of arithmetic, through many rather recondite propositions of symbolic logic, to the "proof" of such truisms as $2+2=4$ : for it is plain that the conclusion is more certain than the premises, and the supposed proof therefore seems futile. But of course what we are really proving is not the 
truth of $2+2=4$, but the fact that from our premises this truth can be deduced (Russell 1907/1973, 272).

Since Russell uses the word "deduced," it may appear that he is describing a purely deductive process, of deriving $2+2=4$ from logical premises. But this is not the case, as Russell goes on to say.

in mathematics, except in the earliest parts, the propositions from which a given proposition is deduced generally give the reason why we believe the given proposition. But in dealing with the principles of mathematics, this relation is reversed. Our propositions are too simple to be easy, and thus their consequences are generally easier than they are. Hence we tend to believe the premises because we can see that their consequences are true, instead of believing the consequences because we know the premises to be true. But the inferring of premises from consequences is the essence of induction; thus the method in investigating the principles of mathematics is really an inductive method, and is substantially the same as the method of discovering general laws in any other science (Russell 1907/1973, 273-274).

Russell uses the law of gravitation as an example of a physical law that is comparable to logical laws, because it "leads to many consequences which could not be discovered merely from the apparent motions of the heavenly bodies" (275). Logical laws, similarly, allow for the discovery of mathematical consequences not discoverable without them, including Peano's axioms and Frege's definition of number:

Peano prefaces his arithmetic by an exposition of symbolic logic; and symbolic logic is used by him in deducing arithmetic from his five premises. Thus the premises of symbolic logic are in any case necessary to arithmetic; if they can be shown to be also sufficient, the five premises will cease to be logical premises, and will take their place as theorems. The first serious attempt in this direction is that of Frege, who showed that a cardinal number may be defined as a class of similar classes (Russell 1907/1973, 277).

The necessity and sufficiency of these premises for arithmetic are not assessed piecemeal. Rather, the probability of the axioms is determined jointly, as they function as a system: 
Assuming the usual laws of deduction, two obvious propositions of which one can be deduced from the other both become more nearly certain than they would be in isolation; and thus in a complicated deductive system, many parts of which are obvious, the total probability may become all but absolute certainty. Thus although intrinsic obviousness is the basis of every science, it is never, in a fairly advanced science, the whole of our reason for believing any one proposition of the science (279).

Nonetheless, if a paradox or contradiction is found in the axiomatic system, Russell argues, then it is important to isolate which of the axioms is responsible for the contradiction and to isolate the consequences of that axiom or axioms from the others. This requires an "experimental" method, since there is no certain way to assess a priori whether an axiom leads to false conclusions. Moreover, we must show that the axiom, or "logical premise," leads correctly to the conclusions claimed for it, and that any modification of the system approaches more closely to a secure derivation:

All this is very like the procedure of other sciences. Boyle's law, e.g. is only approximately true; therefore our premises must both prove it approximately true, and not prove it quite true. Thus Frege's premises undoubtedly give a first approximation, and the exact truth must be very like them (p. 280).

Russell is committed, then, to the following four claims:

R1. A law, such as Boyle's law, that is only approximately true should not be treated in scientific reasoning as exactly true or as absolutely certain, but rather as approaching the truth (or the phenomena) to a given, specific degree of accuracy; Frege's axioms for arithmetic fall into this class.

R2. The regressive method infers laws from observed facts (consequences), including mathematical facts. We may reason from mathematical facts (results) to logical premises, and the logical premises may be more complex than the mathematical facts.

R3. Laws or axioms are sources of fruitfulness: the law of gravitation has more consequences than the phenomena of gravitation, and 
the axioms of logic have more consequences than a list of specific results of mathematics.

R4. The axioms of logic and mathematics, like the laws of physical sciences, are only probably true, but the joint probability of those axioms, given the observed facts or results that can be derived from them, approaches certainty (Russell expresses this position more concretely in Whitehead and Russell 1925, 59).

It is instructive to compare R1-R4 with $\mathrm{J} 1-\mathrm{J} 4$ in the section above. One could make a straightforward claim that the account of the discovery and justification of axioms that Russell is working within that talk is Jevons's. Russell did possess a copy of Jevons's Principles of Science. ${ }^{8}$ And several of Russell's interlocutors around this time, including Bradley, Keynes, and Frege, engage with Jevons's Principles in their work. ${ }^{9}$

Still, there are alternative sources for each idea. ${ }^{10} \mathrm{~J} 2$ could have come to Russell through $\$ 16$ of Frege's Foundations. ${ }^{11} \mathrm{~J} 3$ is a well-known feature of Whewell's account of induction as well as Jevons's. A version of $\mathrm{J} 4$ can be found in Poincarés Science and Method. ${ }^{12}$

The historical point, though, is that the application of the "regressive method" to the axioms of mathematics and of empirical science was broadly established by the end of the nineteenth century. When Russell's "intellectual honeymoon" ended, and he realized the depth of the problems posed by the paradoxes and by the lack of justification for certain axioms, Russell conceived of a new position with respect to the axioms of mathematics and of the relationship between mathematics and logic, a position informed by these earlier discussions.

In the early 1900s, Russell became increasingly aware of the role of certain axioms, including the axioms of reducibility, choice, and infinity, and the multiplicative axiom, in deriving the results of mathematics. One way of reading the title of Russell's talk, "The Regressive Method of Discovering the Principles of Mathematics," is to say that the regressive method helps us to discover the principles of mathematics: the single, fundamental, true laws of logic from which mathematics is derived. But another way to read the title is to say that the regressive method allows us to identify the principles of mathematics that were always at work in, and implicit in, mathematical practice. G. H. Moore (2015) puts it this way: 
The role played by the Axiom of Choice in Russell's work is long and complicated. Like many mathematicians around 1900, he used the Axiom of Choice implicitly without realizing that he had done so, since no one had yet formulated it explicitly (lv).

Russell came to realize the significance of a number of propositions in the early 1900s, including the Axiom of Choice, his own and Whitehead's Multiplicative Axiom, and other related statements then in use. In a letter to Jourdain, he writes,

As for the $\mathrm{X}^{\mathrm{ve}}$ [multiplicative] axiom, I came on it so to speak by chance. Whitehead and I make alternate recensions of the various parts of our book, each correcting the last recension made by the other. In going over one of his recensions, which contained a proof of the $\mathrm{X}^{\mathrm{ve}}$ axiom, I found that the previous prop[osition] used in the proof had surreptitiously assumed the axiom. This happened in the summer of 1904. At first I thought probably a proof could easily be found; but gradually I saw that, if there is a proof, it must be very recondite (Letter of March 15, 1906, reprinted in Grattan-Guiness 1972, 107).

In another work, Moore describes Russell's route to the Multiplicative Axiom:

Russell reached the Multiplicative Axiom by a route quite different from Zermelo's path to the Axiom of Choice. While Zermelo had been preoccupied with the Well-Ordering Problem, Russell's Multiplicative Axiom arose from considering the infinite product of disjoint sets, i.e., their multiplicative class, in order to define the product of infinitely many cardinals. During 1902 Whitehead, who was already collaborating with Russell, had defined the multiplicative class $K^{x}$ of a disjoint family $K$ of non-empty classes: $K^{x}$ is the class of all those sub-classes $M$ of the union of $K$ such that for every $S$ in $K, M \cap S$ has exactly one member. When finally published, Russell's Multiplicative Axiom took the following form (1906, 49):

(2.7.1) If $K$ is a disjoint family of non-empty classes, then $K^{x}$ is non-empty.

... At what point did Russell come to regard (2.7.1) as an axiom? One must understand that when (2.7.1) resisted his attempts to prove it, he became increasingly skeptical of its validity. For Russell, (2.7.1) became Innovations in the History of Analytical Philosophy, edited by Sandra Lapointe, and Christopher Pincock, Palgrave 
an axiom in the sense of a fundamental unproved assertion but not in the sense of a self-evident truth (Moore 2012, 123).

As Moore notes, at first, Russell and Whitehead saw the Multiplicative Axiom as a theorem. At some point, Russell came to realize that a number of results depended on the proposition and came to regard it as an axiom. As Russell later put it, when we reconstruct mathematics and logic as deductive systems, these sorts of dependency relationships become more evident.

When pure mathematics is organized as a deductive system...it becomes obvious that, if we are to believe in the truth of pure mathematics, it cannot be solely because we believe in the truth of the set of premises. Some of the premises are much less obvious than some of their consequences, and are believed chiefly because of their consequences ... With the empirical sciences this is evident. Electro-dynamics, for example, can be concentrated into Maxwell's equations, but these equations are believed because of the observed truth of certain of their logical consequences (Russell 1924/1988, 163-164).

"Belief," here, is not a Keynesian or Bayesian belief in the probability of a proposition given certain evidence. ${ }^{13}$ Rather, it is a belief that the axioms are jointly probable because they recover the intuitive knowledge, "truths of perception," or demonstrated results that are under investigation. As Russell puts it in the introduction to the Principia Mathematica,

The reason for accepting an axiom, as for accepting any other proposition, is always largely inductive, namely that many propositions which are nearly indubitable can be deduced from it, and that no equally plausible way is known by which these propositions could be true if the axiom were false, and nothing which is probably false can be deduced from it. If the axiom is apparently self-evident, that only means, practically, that it is nearly indubitable; for things have been thought to be self-evident and have yet turned out to be false. And if the axiom itself is nearly indubitable, that merely adds to the inductive evidence derived from the fact that its consequences are nearly indubitable: it does not provide new evidence 
of a radically different kind. Infallibility is never attainable, and therefore some element of doubt should always attach to every axiom and to all its consequences. In formal logic, the element of doubt is less than in most sciences, but it is not absent, as appears from the fact that the paradoxes followed from premisses which were not previously known to require limitations (Whitehead and Russell 1925, 59).

Russell's aim is to reconstruct mathematics as a deductive system, using the method of analysis. That method requires using the regressive method to "discover" which are the axioms of mathematics, as opposed to the theorems, which requires identifying the structural and logical relationships of dependence within a theory.

One of the best descriptions of how such relationships can be identified can be found in Frege-and in a discussion of Jevons. In $\$ 15$ of the Foundations, Frege cites Jevons as making "A very emphatic declaration in favor of the analytic nature of the laws of logic," that "I hold that algebra is a highly developed logic, and number but logical discrimination." 14 Just below, Frege argues that the laws of number could be inferred as follows:

Instead of linking our chain of deductions direct to any matter of fact, we can leave the fact on one side, while adopting its content in the form of a condition. By substituting in this way conditions for facts throughout the whole of a train of reasoning, we shall finally reduce it to a form in which a certain result is made dependent on a certain series of conditions. This truth would be established by thought alone ... It is not impossible that the laws of number are of this type. This would make them analytic judgments, despite the fact that they would not normally be discovered by thought alone; for we are concerned here not with the way in which they are discovered but with kind of the ground on which their proof rests ... It would then rest with observation finally to decide whether the conditions included in the laws thus established are actually fulfilled ( $\$ 16$, emphasis added).

Whether a judgment made in this way is "analytic" has to do with whether a judgment is derived independently of empirical facts, not 
with whether it is an a priori, necessary truth - in fact, Frege concludes above that such a judgment must be checked afterward.

Frege merely suggests a "conditional" approach, following his citation of Jevons's claim that the laws of logic are analytic. However, in the Preface and Introduction to the Grundgesetze, Frege argues that the laws of logic should be identified as immanent in the proofs of arithmetic, and his discussion makes reference to a hypothetical method:

The completeness in the chains of inference ensures that each axiom, each assumption, each hypothesis... upon which a proof is based, is brought to light; and so a basis is gained for judging the epistemological nature of the law that is proved (Frege 1893/1997, 195, translation slightly amended).

Frege's endorsement of a hypothetical or axiomatic method is in the service of the purification of logical inference, not a way of justifying the laws of logic themselves. Nonetheless, Frege mentions Jevons as a source and sketches a method for deriving mathematical or logical results from "a certain series of conditions" ( $\$ 16$, cited above).

Since Russell comes to reject epistemic logicism as a result of the paradoxes and his doubts of the truth of certain axioms (Irvine 1989), he develops a kind of immanent logicism that applies the method of analysis to the axioms of mathematics. For Russell, distinguishing axioms from theorems is not just a matter of tracing back lines of dependence via the regressive method. The regressive method is only one of Russell's modes of analysis, as Beaney (2003) observes:

we may distinguish three core modes of analysis... the regressive mode, concerned to identify the "starting-points" (principles, premisses, causes, etc.) by means of which something can be "explained" or "generated", the resolutive mode, concerned to identify the elements of something and the way they interrelate, and the interpretive mode, concerned to "translate" something into a particular framework (154). 
The "resolutive" mode is what is usually identified with logical analysis: "the decomposition of something, and in particular, a concept or proposition, into its constituents, where this may also include its form or structure" (Beaney 2003, 155). Beaney points out that both the regressive and resolutive modes presuppose the third:

Any analysis presupposes a particular framework of interpretation, and work is done in interpreting what we are seeking to analyse - the analysandum as part of the process of disclosing what is more fundamental (155-156).

Only under a certain interpretation is one proposition more fundamental than another, for instance-a fact that Quine would employ later to radical effect. ${ }^{15}$ One fascinating question in the scholarship of logicism is whether Frege, or Russell, can allow for differing interpretations or frameworks. Of course, one can be a logicist_even a Fregean—and can say that different frameworks can be considered hypothetically, on the way to discovering the final, true set of laws or fundamental propositions of a science.

Russell's regressive method for discovering the axioms of mathematics should be read in the larger context of the method of analysis and of what I've called immanent logicism. Mathematicians may use axioms, logical concepts, logical presuppositions, and the like implicitly. Discovering those axioms or presuppositions may require formulating premises that are much more complicated than the conclusions they support, which seems to be a direct contradiction of the logicist requirement that complex mathematical results should be derived from simpler logical laws and rules of inference.

But the regressive discovery of the axioms on which certain inferences or results depend is not, in and of itself, a Russellian analysis of the logical structures of dependence of a theory, or of the fundamental logical conditions for mathematical results. The regressive moment should be understood as a step along the way to delineating those structures of dependence. The method of analysis also requires resolving the propositions and theories at issue into their proper elements and identifying the interpretation or framework for the analysis of a given theory. 
Moreover, accepting an axiom as fundamental under a given framework, as a regressive condition for recovering certain results of a theory, does not require accepting that axiom as true. It can be indispensable to a result, in Quine's and Putnam's later sense. ${ }^{16}$ But it does not have to be true under Frege's definition. Nor does such an axiom, in the framework of Russell's method, have to be a statement in a universal logical language. ${ }^{17}$ In that sense, Russell can avoid Sheffer's logocentric predicament.

Why does Russell allow for this broader, conditional sense of logicism? If logic is to be regarded as a "first science," and as the language in which all other sciences are expressed, it must be possible to discover the logical relationships within scientific theories. If that is to be the case, then those theories, themselves, must be the evidence given for those relationships. Any logical explanation of a theoretical structure or relationship of dependence should recapture the result of the theory that is being explained. If the above statements do not obtain, then one underlying motivation for logicism is weakened: its status as "first science."

Logicism, then, involves not just particular commitments about the derivability of statements or results from logic. It can be seen, as well, as a commitment to the claim that the structures and relations of dependence within theories are logical. The Russellian logicist believes that while puzzles, paradoxes, and problems may persist, they also may reveal an underlying relational structure that, if interpreted properly, extends our knowledge. ${ }^{18}$ The confidence that there is such a structure to be found is the basis of Russell's immanent logicism, and of his employment of the method of analysis in logic and in mathematics.

\section{Notes}

1. See Ricketts (1985) for a discussion of this distinction and Wittgenstein's objection, that "the status Frege assigns to inference rules characterizes all of logic; as a consequence, there are, in Frege's sense, no logical laws" (p. 4).

2. Russell (1905b, 1906), see also Lakatos (1962/1980), 18 and passim.

3. Or even "inductive," though I will not explore this terminological subtlety further. 
4. Russell (1912), ch. 11; Russell (1924/1988), 163f. Christopher Pincock recognized the relevance of Problems to this discussion.

5. Irving (1989), 314; the citation is from Russell (1959), 76.

6. See Schabas (1990), ch. 4 for Herschel's influence on Jevons.

7. The principles thus achieved are "believed chiefly because of their consequences" (Russell 1924/1988, 163). See Section 3 of Irvine (1989) for a fuller discussion of Russell's claim.

8. There are no notes in the copy preserved in the Bertrand Russell Archives, nor do the Archives possess notes made elsewhere. I am grateful to Nicholas Griffin for this information and also for pointing out that this does not mean such notes do not exist. As Christopher Pincock observed in correspondence, there are references to Jevons in volume 1 of Russell's Collected Papers (1983), but these do not appear to be relevant to the current context $(254,356)$.

9. Bradley discusses Jevons's Principles extensively in The Principles of Logic, and writes in the conclusion to Book II, Part II, Ch. 4 that "no living Englishman has done half the service to logic that Professor Jevons has done ... And there can not be anyone who has left unread the Principles of Science, who has not something to learn from it" $(1883,360)$. Bradley disagreed with Jevons's methodology, and this remark is made after many pages of criticism. But the criticism and the praise both demonstrate that Bradley had engaged seriously with the text. Frege's citation of Jevons is given below (Foundations 1884/1974, \$16). Keynes discusses the Principles in Keynes (1921), 43 and especially 243ff.

10. In comments on a draft, Greg Frost-Arnold pointed out that Russell and Jevons could have picked up these ideas from a common source. I now believe this to be true in some cases. My aim is not to prove a direct influence of one author on another, but rather that Russell was influenced by this renewed interest in regressive justification.

11. This would be an influence, but an indirect one.

12. Russell reviewed Science and Hypothesis twice for Mind (1905b, 1906), though somewhat unfavorably. He wrote a preface to the 1914 English edition of Science and Method.

13. Russell discusses why he does not accept this in Russell (1922).

14. Frege cites the second edition of Principles.

15. Morris (2015) argues that Quine's naturalism owes a debt to Russell's "moves toward a scientific philosophy" (p. 151).

16. Audrey Yap remarked on the relevance of Quine-Putnam indispensability to this discussion. 
17. See Korhonen (2012) for an extensive discussion of the relevance of this question for Frege and for Russell.

18. "A logical theory may be tested by its capacity for dealing with puzzles, and it is a wholesome plan, in thinking about logic, to stock the mind with as many puzzles as possible, since these serve much the same purpose as is served by experiments in physical science" (Russell 1905a, 484-485).

Acknowledgements Many thanks are due to Sean Morris for pointing me to Russell's 1907 talk, "The Regressive Method of Discovering the Premises of Mathematics." Soon thereafter, Richard Burian donated a number of offprints to the Virginia Tech philosophy department, and I found Larry Laudan's 1968 paper on theories of scientific method there. I traced Jevons's Principles following a lead from that paper, and noticed a number of similarities with the Russell talk. I am grateful to Sandra Lapointe and Chris Pincock for inviting me to contribute to this volume, and for detailed comments on an earlier draft. Professors Lapointe and Pincock organized a very productive workshop with the contributors in Hamilton, Ontario. The paper has profited from insightful suggestions at the workshop from Daniel Harris, Jeremy Heis, Colin Johnston, Alexander Klein, Marcus Rossberg, Dirk Schlimm, and Audrey Yap. I owe a debt to Nicholas Griffin for discussing the role of Jevons, for consulting the Bertrand Russell Archives at McMaster University, and for putting me on the right track in correspondence. Greg Frost-Arnold sent detailed and perceptive comments on the draft afterward. A final conversation with Christopher Pincock brought the central argument of the paper into much sharper focus. None of these are to blame for my errors or wrong turnings.

\section{References}

Beaney, Michael. 2003. "Russell and Frege". In The Cambridge Companion to Russell, Nicholas Griffin, ed. Cambridge: Cambridge University Press. Blanchette, Patricia. 2012. Frege's Conception of Logic. Oxford: Oxford University Press.

Bradley, Francis. 1883. The Principles of Logic. London: Clarendon Press. Frege, Gottlob. 1884/1974. The Foundations of Arithmetic, 2nd ed. trans.

Austin. UK: Blackwell. 
. 1893/1997. Grundgesetze der Arithmetik. In The Frege Reader, ed. Beaney, Michael, 194-223. Malden, MA: Blackwell.

Gandon, Sébastien. 2012. Russell's Unknown Logicism. London: Palgrave McMillan.

Godwyn, Martin and Irvine, Andrew. 2003. "Bertrand Russell's Logicism”, pp. 171-201 in Griffin 2003.

Goldfarb, Warren. 1982. "Logicism and logical truth". Journal of Philosophy 79: 692-695.

Grattan-Guinness, Ivor. 1972. "Bertrand Russell on His Paradox and the Multiplicative Axiom. An Unpublished Letter to Philip Jourdain”. Journal of Philosophical Logic 1 (2): 103-110.

Hager, Paul. 2003. "Russell's Method of Analysis", pp. 310-331 in Griffin 2003. Irvine, Andrew. 1989. "Epistemic Logicism \& Russell's Regressive Method". Philosophical Studies 55 (3): 303-27.

Irvine, Andrew. 2009. "Bertrand Russell's Logic". In Handbook of the History of Logic, vol. 5, ed. Gabbay and Woods, 1-28. Amsterdam: Elsevier.

Jevons, William Stanley. 1874. Principles of Science. London: Richard Clay \& Sons.

Keynes, John Maynard. 1921. A Treatise on Probability. London: Macmillan.

Korhonen, Anssi. 2012. "Logic as a Science and Logic as a Theory: Remarks on Frege, Russell and the Logocentric Predicament". Logica Universalis 6: 597-613.

Kremer, Michael. 2006. "Logicist Responses to Kant: (Early) Frege and (Early) Russell”. Philosophical Topics 34 (1/2): 163-188.

Lakatos, Imre. 1962/1980. "Infinite Regress and Foundations of Mathematics". In Mathematics, Science and Epistemology: Volume 2, ed. Worrall and Currie, 3-23. Cambridge: Cambridge University Press.

Laudan, Larry. 1968. "Theories of Scientific Method from Plato to Mach," History of Science 7: 1-63.

Moore, G.H. 2012. Zermelo's Axiom of Choice: Its Origins, Development, and Influence. Dordrecht: Springer.

Moore, G.H. 2015. "Introduction" to Russell, Bertrand. In The Collected Papers of Bertrand Russell, Volume 5: Toward Principia Mathematica, ed. G.H. Moore, 1905-1908. London: Routledge.

Morris, Sean. 2015. "Quine, Russell, and Naturalism," Journal of the History of Philosophy 53 (1): 133-155.

Quine, W.V. 1936/1976. "Truth by Convention”. In The Ways of Paradox, 77-106, rev. ed. Cambridge: Harvard University Press. 
Ricketts, Thomas. 1985. "Frege, the Tractatus, and the Logocentric Predicament," Noûs 19 (1): 3-15.

Russell, Bertrand. 1905a. "On Denoting," Mind 14: 479-493.

$412-418$.

1905b. "Review" [of Poincarés Science and Hypothesis], Mind 14 (55):

—. 1906. “M. Poincaré's Science et Hypothèse," Mind 15 (57): 141-143.

. 1907/1973. "The Regressive Method of Discovering the Premises of

Mathematics”. In Essays in Analysis, ed. Douglas Lackey, 272-283. London:

George Allen \& Unwin Ltd.

- 1912. The Problems of Philosophy. London: Williams and Norgate.

- 1922. "Review" of Keynes's. A Treatise on Probability. The Mathematical Gazette 11 (159): 119-125.

- 1924/1988. "Logical Atomism". In Essays on Language, Mind, and Matter, ed. Slater, 160-179. London: Unwin Hyman.

- 1959. My Philosophical Development. New York: Simon \& Schuster.

- 1983. The Collected Papers of Bertrand Russell, Volume 1: Cambridge Essays, 1888-1899, ed. Kenneth Blackwell, Andrew Brink, Nicholas Griffin, Richard A. Rempel and John G. Slater. London and New York: George Allen \& Unwin Ltd.

Russell, Gillian. 2014. "Metaphysical Analyticity and the Epistemology of Logic," Philosophical Studies, 1-15.

Schabas, Margaret. 1984. “The 'Worldly Philosophy' of William Stanley Jevons," Victorian Studies 28 (1): 129-47.

Schabas, Margaret. 1990. A World Ruled by Number. Princeton: Princeton University Press.

Sheffer, Harry. 1926. "Review of Principia Mathematica, vol. I, 2nd edn." Isis 8: 226-231.

Venn, John. 1889. The Principles of Empirical or Deductive Logic. London: Macmillan.

- 1866. The Logic of Chance. London: Macmillan.

Whitehead, Alfred North and Russell, Bertrand. 1925. Principia Mathematica, vol. 1, 2nd ed., first ed. 1910. Cambridge: Cambridge University Press. 